\title{
Emotional abuse of girls in Swaziland: prevalence, perpetrators, risk and protective factors and health outcomes
}

Franziska Meinck ${ }^{1,2}$, Deborah Fry 3 , Choice Ginindza ${ }^{4}$, Kerri Wazny ${ }^{3}$, Aldo Elizalde ${ }^{5}$, Thees F Spreckelsen ${ }^{1}$, M Catherine Maternowska $^{6}$, Michael P Dunne ${ }^{7}$

${ }^{1}$ University of Oxford, Oxford, England, UK

${ }^{2}$ OPTENTIA, School of Behavioural Sciences, North-West University, Vanderbijlpark, South Africa

${ }^{3}$ Moray House School of Education, University of Edinburgh, Edinburgh, Scotland, UK

${ }^{4}$ Swaziland Central Statistical Office, Mbabane, Swaziland

${ }^{5}$ Institute of Health and Wellbeing, University of Glasgow, Glasgow, Scotland, UK

${ }^{6}$ UNICEF Office of Research - Innocenti, Florence, Italy

${ }^{7}$ School of Public Health and Social Work, Queensland University of Technology, Brisbane, Australia
Background Research on emotional child abuse in sub-Saharan Africa is scarce. Few studies thus far have examined prevalence, risk and protective factors for emotional child abuse or the associations between emotional abuse and girls' health.

Methods A nationally representative two-stage, cluster-sampled, household survey of females aged $13-24$ years $(n=1244)$ on childhood abuse victimisation was conducted. Participants completed interviewer-assisted questionnaires. Associations between emotional abuse and putative risk, and protective factors and health outcomes were analyzed using separate logistic regression models accounting for sampling design. Marginal effects of cumulative risk factors for emotional abuse victimisation were examined.

Results Lifetime prevalence of emotional abuse was 28.5\% with $58.3 \%$ of these girls reporting many abusive incidents. The most common perpetrators were female $(27.8 \%)$ and male (16.7\%) relatives and, more rarely, biological parents. Risk factors associated with emotional abuse were frequent caregiver changes (odds ratio (OR) 1.42, 95\% confidence interval (CI) 1.03-1.970, poverty (OR 1.51, 95\% CI 1.12-2.03), physical abuse (OR 1.98, 95\% CI 1.45-2.71) and sexual abuse (OR 2.22, 95\% CI 1.57-3.10) victimisation. Being close to one's mother was a protective factor (OR 0.88, 95\% CI 0.80-0.97). Risk for emotional abuse increased from $13 \%$ with no risk factors present to $58.4 \%$-with all four risk factors present. Health outcomes associated with emotional child abuse were suicidal ideation (OR 1.85, 95\% CI 1.30-2.63) and feeling depressed (OR 1.89, 95\% CI 1.31-2.71).

Conclusions Girls in Swaziland experience high levels of emotional abuse victimisation. Emotional abuse is associated with economic disadvantage, family factors, other types of abuse victimisation and poor mental health. Therefore, a holistic approach to prevention is needed, incorporating poverty reduction and programmes to improve parentchild relationships, reduce the use of harsh criticism, and change parenting social norms.

Worldwide, millions of children are victims of abuse and neglect [1], with children in the sub-Saharan African region suffering from particularly high rates of abuse $[2,3]$. Child maltreatment in the region is associated with a large range of negative outcomes including substance use [4], mental health problems [5], re-victimisation [6], and HIV-risk behavior [7].

A recent systematic review of risk factors for child abuse victimisation in Africa found a growing body of evidence on factors associated mainly with 
physical and sexual abuse victimisation [8]. Factors pertaining to emotional child abuse, however, are understudied. In fact, across the sub-Saharan region, only a few quantitative studies have investigated determinants or consequences of emotional child abuse, mostly in conjunction with other adverse childhood experiences [5,9-11]. Available research on emotional abuse alone presents a range of findings depending on the measurements used: living or having lived with a step-father [12], witnessing domestic violence [13], having a caregiver who is ill with AIDS or being AIDS-orphaned [7,11], living with someone who is chronically ill, poverty [14], poor family functioning [15] and poor caregiver mental health [13,15]. Countries across sub-Saharan Africa are culturally and socioeconomically diverse with differing services available to children and abuse victims. Therefore, country-specific research on prevalence and factors associated with emotional child abuse is important for the design of prevention and care policies and programs.

In Swaziland, research on emotional abuse has mostly focused on abuse perpetrated by teachers [16] and the use of humiliating punishment [17]. Some studies have identified drivers of physical and emotional violence against children in Swaziland such as poverty $[17,18]$, orphanhood and moving to live with a different caregiver [18]. However, none of these studies used a nationally representative sample of children to investigate factors associated with emotional child abuse.

The current study had four aims: 1) to estimate the prevalence of childhood emotional abuse and frequency of victimisation, along with the most common perpetrators of emotional abuse among girls in Swaziland; 2) to investigate potential risk and protective factors for emotional abuse 3) to examine whether there is a cumulative risk for emotional abuse when more than one risk factor is present; and 4) to identify associations between emotional abuse and health outcomes.

\section{METHODS}

The analyses presented below are part of the Violence Against Girls Study in Swaziland. The Government of Swaziland had the responsibility for the overall study design and management of the national survey with technical leadership provided by the Central Statistical Office in collaboration with UNICEF Swaziland and the United States Center for Disease Control and Prevention (CDC). The study's overarching aim was to describe epidemiological patterns of sexual violence, identify risk factors, assess knowledge and utilization of services available to victims of sexual violence and to improve awareness of sexual violence against girls [19]. It is to date the only nationally representative survey of girls in Swaziland.

\section{Procedure}

From May 2007 to June 2007, a nationally representative household survey of 13-24 year-old females was conducted using a two-stage, cluster survey design. In the first stage, 40 enumerator areas were selected. In the second stage, a systematic sample of 48 households in each enumerator area with a random start was selected. The sampling frame was provided by the Central Statistics Office of Swaziland based on the 1997 population census. A total of 1900 households were visited, of which 68\% (1292) had an eligible female (aged 13-24 years). Overall response rate was 96.3\% with $1.1 \%(\mathrm{n}=14)$ refusals and $2.6 \%$ $(n=34)$ unavailability [19], which is comparable to other studies in the region [20], and resulted in data from 1244 individuals. One eligible participant was interviewed per household. Where more than one eligible girl was resident, a single participant was randomly selected using the Kish Method [20]. The interview schedule was developed using standardised questionnaires with the help of local informants and were pre-tested through piloting. Interviews were carried out in SiSwati and no incentives were provided. More information on sampling and methodology are available from previous publications on Violence Against Girls in Swaziland [21-23].

Ethical approval was granted by the CDC's Institutional Review Board, and ethics and safety guidelines for studies on violence against women were followed [24,25]. Voluntary consent was obtained from all participants and their head of household. Questionnaires were completed with the help of female interviewers who had received extensive training on privacy, confidentiality and talking about sensitive themes. Participants could stop the interview at any time or skip questions and were given a list of organisations that provide services for women and children.

\section{Measures}

Emotional abuse was measured using one item: "When you were growing up, did any adults scare you or make you feel really bad because they called you names, said mean things to you, or said they didn't want 
you?" Any emotional abuse that was carried out by an adult such as a biological parent, another relative, a partner, teacher, community or church leader when the participant was aged $<18$ was included in this analysis.

Physical abuse was measured using one item on being kicked, bitten, slapped, hit with a fist or an item, or threatened with a weapon. Contact sexual abuse was measured using five items on forced sexual inter-

Table 1. Socio-demographic characteristics of the sample of girls in Swaziland, $2007(n=1224) *$

\begin{tabular}{|c|c|c|}
\hline Characteristics & Percentage (M) & Confidence Interval (95\% \\
\hline Child emotional abuse & $28.5 \%(355)$ & $25.8-31.4 \%$ \\
\hline Child sexual abuse & $49.3 \%(613)$ & $46.2-52.5 \%$ \\
\hline Child physical abuse & $25.6 \%(319)$ & $22.5-27.8 \%$ \\
\hline Orphanhood & $43.7 \%(544)$ & $40.6-47.9 \%$ \\
\hline Paternal orphanhood & $33.0 \%(411)$ & $30.4-36.4 \%$ \\
\hline Maternal orphanhood & $10.8 \%(134)$ & $9.0-12.9 \%$ \\
\hline \multicolumn{3}{|l|}{ Community trust: } \\
\hline -Strongly disagree & $13.7 \%(170)$ & $11.7-16.1 \%$ \\
\hline -Disagree & $39.6 \%(493)$ & $36.6-42.7 \%$ \\
\hline -Neither agree nor disagree & $18.8 \%(234)$ & $16.4-21.5 \%$ \\
\hline -Agree & $22.0 \%(274)$ & $19.6-24.6 \%$ \\
\hline -Strongly agree & $5.7 \%(71)$ & $4.5-7.4 \%$ \\
\hline \multicolumn{3}{|l|}{ School trust: } \\
\hline -Not at all trusting & $9.0 \%(112)$ & $7.3-11.0 \%$ \\
\hline -Somewhat trusting & $31.1 \%(387)$ & $28.2-34.1 \%$ \\
\hline -Very trusting & $59.9 \%(745)$ & $56.8-62.9 \%$ \\
\hline \multicolumn{3}{|l|}{ Religious practice: } \\
\hline -Not important & $7.2 \%(90)$ & $5.8-9.0 \%$ \\
\hline -A little important & $5.4 \%(67)$ & $4.1-7.0 \%$ \\
\hline -Somewhat important & $16.0 \%(199)$ & $13.8-18.5 \%$ \\
\hline -Very important & $71.4 \%(888)$ & $68.5-74.1 \%$ \\
\hline Poverty & $58.5 \%(728)$ & $55.5-61.4 \%$ \\
\hline Overcrowding & $87.8 \%(1092)$ & $85.8-89.5 \%$ \\
\hline Close to mother & $75.9 \%(944)$ & $73.2-78.9 \%$ \\
\hline Close to father & $46.6 \%(580)$ & $43.5-49.7 \%$ \\
\hline Frequent caregiver changes & $26.1 \%(325)$ & $23.5-28.9 \%$ \\
\hline Age (years) & 17.9 (SE 0.10) & $17.8-18.1$ \\
\hline \multicolumn{3}{|l|}{ Relationship status: } \\
\hline -Married & $9.7 \%(120)$ & $8.1-11.7 \%$ \\
\hline -Living with partner, not married & $3.4 \%(42)$ & $2.5-4.4 \%$ \\
\hline -Not living with partner & $86.8 \%(1079)$ & $84.7-88.7 \%$ \\
\hline Urban or peri-urban area & $15.3 \%(190)$ & $14.5-16.3 \%$ \\
\hline Ethnicity African & $99.8 \%(1241)$ & $99.2-99.9 \%$ \\
\hline \multicolumn{3}{|l|}{ Highest level of education: } \\
\hline -Some primary & $43.4 \%(538)$ & $40.3-46.5 \%$ \\
\hline -Some secondary & $55.2 \%(687)$ & $52.0-58.3 \%$ \\
\hline -Some tertiary & $1.4 \%(17)$ & $0.7-2.4 \%$ \\
\hline \multicolumn{3}{|l|}{ Religion: } \\
\hline -Zionist Christian Church & $41.0 \%(510)$ & $38.1-44.1 \%$ \\
\hline -Catholic & $5.4 \%(67)$ & $4.2-6.9 \%$ \\
\hline -Protestant & $52.7 \%(656)$ & $49.6-55.8 \%$ \\
\hline -Muslim & $0.1 \%(1)$ & $0.002-0.04 \%$ \\
\hline Suicidal ideation & $17.7 \%(220)$ & $15.5-20.0 \%$ \\
\hline Feeling depressed & $67.8 \%(843)$ & $64.8-70.6 \%$ \\
\hline Sexually transmitted diseases & $5.0 \%(62)$ & $3.7-6.6 \%$ \\
\hline Alcohol & $10.3 \%(128)$ & $8.6-12.4 \%$ \\
\hline HIV-positive & $12.0 \%(149)$ & $8.7-16.2 \%$ \\
\hline Smoking & $2.0 \%(25)$ & $1.3-3.0 \%$ \\
\hline
\end{tabular}

SE - standard error

* Some variation in numbers across variables due to a small amount of missing data. course, coerced sexual intercourse, attempted forced intercourse, and forced sexual touching. The participant had to be $<18$ years old when the first such incident occurred.

Abuse frequency was measured for each perpetrator with a response code of "never; once; few; and many".

Orphanhood was defined as having lost one or both parents during childhood [26]. Participants were also asked how close to their biological mother or father they felt.

Overcrowding was measured asking for the largest number of people who lived in the home at any point in time and defined as $>5$. Frequent caregiver changes were measured using one item establishing how many different families the participant had lived with in their lifetime and defined as having moved family $>3$. Poverty was measured using the proxy food insufficiency which was defined as going hungry often or sometimes. Community trust was measured using an item on trusting people in the neighborhood/community/village. School trust was measured using one item establishing how trusting the child was of teachers and school administrators.

Mental health and health risk behaviors were not comprehensively measured in this interview, although indicators of possible mental health problems included one item on depression ("have you ever felt depressed?"), two items on suicidal ideation ("have you ever thought about suicide and attempted suicide?"), one item on smoking cigarettes, and ever drinking alcohol, ever having had a sexually transmitted disease, and being HIVpositive.

Other socio-demographic information was also collected: the importance of religion, faith, highest level of education, marital status, whether they lived in urban/ peri-urban or rural locations, and their age.

Most of the items used in this survey have been used successfully in multiple Violence Against Children (VAC) studies $[23,27,28]$.

\section{Analysis}

Four analyses steps were conducted using Stata 13 (StataCorp, College Station, Texas, USA), each accounting for the clustered sampling design. First, descriptive statistics for emotional abuse, risk factors, health outcomes and covariates were obtained (Table 1). Second, bivariate regressions were used to investigate associations among emotional abuse, hypothesized risk factors and health indicators (Table 2). Third, all significant 
Table 2. Factors associated with emotional abuse victimisation among girls in Swaziland, 2007 using bivariate logistic regressions $(n=1244)$

\begin{tabular}{|c|c|c|}
\hline Factor & $\begin{array}{c}\text { Odds ratio } \\
\text { (95\% CONFIDENGE InTERVaL) }\end{array}$ & P-value \\
\hline Physical abuse & $2.55(1.89-3.44) \ddagger$ & 0.001 \\
\hline Orphanhood & $1.44(1.09-1.90) \dagger$ & 0.009 \\
\hline Sexual abuse & $2.11(1.59-2.80) \ddagger$ & 0.001 \\
\hline \multicolumn{3}{|l|}{ Community trust (very low ref): } \\
\hline -Low & $0.70(0.46-1.07)$ & 0.103 \\
\hline -Undecided & $0.61(0.37-1.00) *$ & 0.049 \\
\hline -High & $0.73(0.46-1.15)$ & 0.180 \\
\hline -Very high & $0.93(0.47-1.83)$ & 0.838 \\
\hline \multicolumn{3}{|l|}{ School trust (low trust ref): } \\
\hline -Medium trust & $0.89(0.53-1.48)$ & 0.640 \\
\hline -High trust & $0.97(0.60-1.58)$ & 0.782 \\
\hline Religious practice & $0.94(0.80-1.10)$ & 0.451 \\
\hline Poverty & $1.48(1.12-1.96) *$ & 0.005 \\
\hline Overcrowding & $1.18(0.78-1.78)$ & 0.428 \\
\hline Close to mother & $0.85(0.77-0.92) \ddagger$ & 0.001 \\
\hline Close to father & $0.94(0.88-1.01)$ & 0.119 \\
\hline Frequent caregiver changes & $1.64(1.21-2.22) \ddagger$ & 0.001 \\
\hline Age & $0.97(0.94-1.01)$ & 0.147 \\
\hline \multicolumn{3}{|l|}{ Level of education primary (ref): } \\
\hline -Some secondary & $0.84(0.63-1.12)$ & 0.229 \\
\hline -Some tertiary & $0.10(0.01-0.78) *$ & 0.028 \\
\hline \multicolumn{3}{|l|}{ Relationship status: } \\
\hline -Married & $1.31(0.85-2.04)$ & 0.225 \\
\hline -Living with partner, not married & $1.17(0.63-2.20)$ & 0.614 \\
\hline \multicolumn{3}{|l|}{-Not living with partner (ref) } \\
\hline Urban or peri-urban area & $0.72(0.50-1.02)$ & 0.066 \\
\hline \multicolumn{3}{|l|}{ Faith: } \\
\hline -Catholic (Ref Zionist Christian) & $0.56(0.30-1.02)$ & 0.062 \\
\hline -Protestant & $0.83(0.62-1.10)$ & 0.197 \\
\hline -No religion & $1.62(0.42-6.27)$ & 0.480 \\
\hline HIV-positive & $0.96(0.47-1.99)$ & 0.918 \\
\hline Drinks alcohol & $1.25(0.79-1.96)$ & 0.335 \\
\hline Smoking & $0.91(0.38-2.18)$ & 0.839 \\
\hline Suicide ideation & $2.23(1.61-3.07) \ddagger$ & 0.001 \\
\hline Feeling depressed & $2.15(1.55-2.97) \ddagger$ & 0.001 \\
\hline Sexually transmitted disease & $2.39(1.29-4.41) \dagger$ & 0.006 \\
\hline
\end{tabular}

risk factors (at $P<0.05$ ) obtained from the bivariate regression were included in two multivariate models with controls for age, urban/rural location and faith. This resulted in five regression models: risk factors for emotional abuse (Table 3, Models 1, 2 and 3) and health outcomes (Table 4, Models 1 and 2) showing model selection through backward elimination of non-significant risk factors until all remaining factors were associated with emotional abuse $(P<0.05)$ [29]. The first risk factor model includes all significant factors $(P<0.05)$ from the bivariate regressions (Model 1). The second includes all factors significant at $P<0.1$ and the third includes all factors significant at $P<0.05$. For the health outcome models, the first includes all risk factors significant at $P>0.1$. The second includes all factors significant at $P<0.05$. Finally, cumulative risk of associated factors was tested. For all risk factor variables and covariates that were included in Table 3 Model 3, marginal effects for emotional abuse - based on the logistic regression model - were calculated with all covariates held at their mean value (average marginal effect). This determined how the predicted probability of the outcome changes for different risk factors (and combinations of risk factors; see Figure 1).

\section{RESULTS}

1244 girls (mean age 17.9 years, 99.8\% Black African) were interviewed in this study. Sample characteristics showed high levels of deprivation: $43.7 \%$ were orphaned, $58.5 \%$ experienced poverty to the point where there was insufficient food in the household, 26.1\% experienced frequent caregiver changes and $87.8 \%$ lived in overcrowded accommodation. Of the participants, $67.8 \%$ reported feeling depressed, $17.7 \%$ suffered from suicidal ideation, $12.0 \%$ were HIV-positive and $5.0 \%$ had a sexually transmitted disease in the past (Table 1 ).

\section{Prevalence of emotional abuse in childhood}

Nearly three in every ten participants (28.5\%, 95\% CI 25.8\%$31.4 \%$ ) reported experiencing emotional abuse at least once

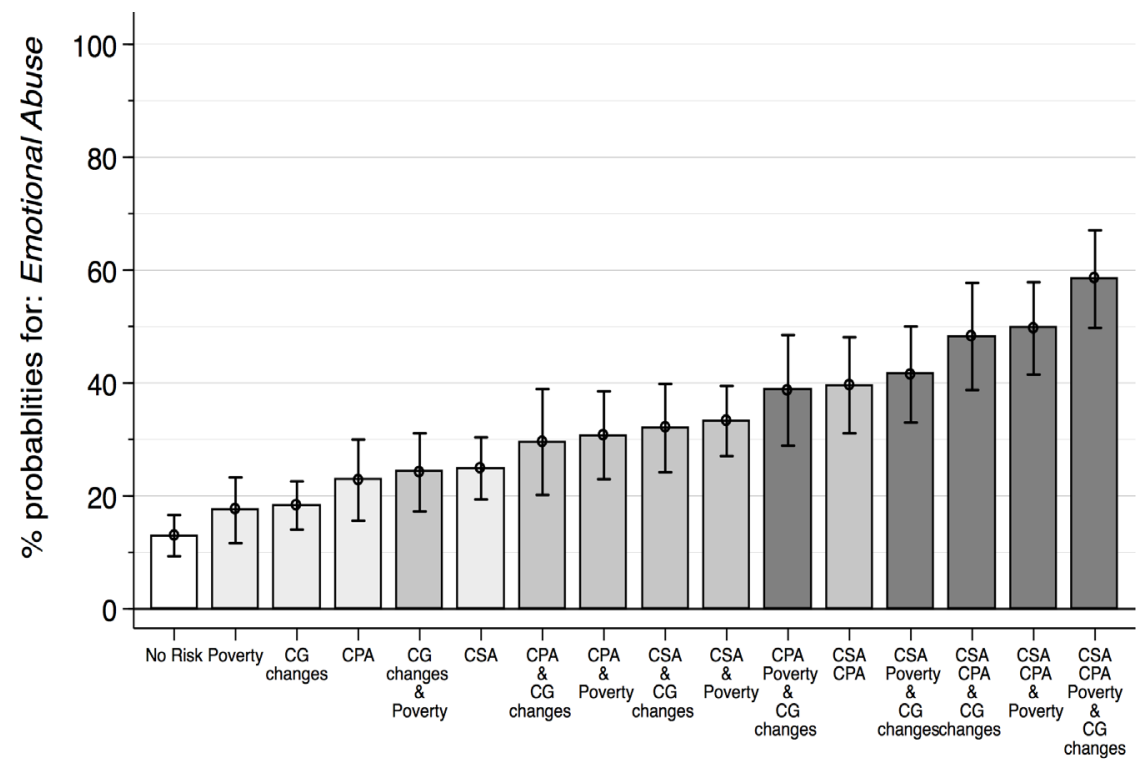

Figure 1. Predicted cumulative risk for emotional abuse victimisation among girls in Swaziland, 2007. Data source: VACS Swaziland, $\mathrm{n}=1224$. 
Table 3. Multivariate logistic regressions of factors associated with emotional abuse among girls in Swaziland, 2007 $(\mathrm{n}=1244)$

\begin{tabular}{|c|c|c|c|c|c|c|}
\hline & \multicolumn{2}{|c|}{ MODEL 1} & \multicolumn{2}{|c|}{ MODEL 2} & \multicolumn{2}{|c|}{ Model 3} \\
\hline & Odds ratio & $95 \%$ CI & Odds ratio & $95 \%$ CI & Odds ratio & $95 \%$ CI \\
\hline Orphanhood & 1.26 & $0.94-1.70$ & & & & \\
\hline Close to mother & $0.91 \dagger$ & $0.82-1.00$ & $0.88 \dagger$ & $0.80-0.89$ & 0.88 † & $0.80-0.97$ \\
\hline Frequent caregiver changes & $1.40 \dagger$ & $1.00-1.97$ & $1.41 \dagger$ & $1.01-1.97$ & $1.42 \dagger$ & $1.03-1.97$ \\
\hline Poverty & $1.45 \dagger$ & $1.07-1.96$ & $1.52 \ddagger$ & $1.13-2.05$ & $1.51 \ddagger$ & $1.12-2.03$ \\
\hline Physical abuse & $2.00 \S$ & $1.45-2.75$ & 1.988 & $1.44-2.72$ & 1.988 & $1.45-2.71$ \\
\hline Sexual abuse & 2.198 & $1.55-3.09$ & $2.14 \S$ & $1.52-2.01$ & 2.228 & $1.57-3.10$ \\
\hline Tertiary education & $0.17 *$ & $0.02-1.32$ & 0.16 & $0.20-1.22$ & & \\
\hline Urban or peri-urban area & $0.64 *$ & $0.43-0.96$ & $0.64 \dagger$ & $0.43-0.96$ & $0.65 \dagger$ & $0.44-0.96$ \\
\hline Age & 0.928 & $0.88-0.97$ & $0.92 \ddagger$ & $0.88-0.97$ & $0.92 \S$ & $0.88-0.97$ \\
\hline Faith & 0.93 & $0.80-1.08$ & & & & \\
\hline
\end{tabular}

CI - confidence interval

* Statistically significant at $P<0.1$.

$\dagger$ Statistically significant at $P<0.05$.

$¥$ Statistically significant at $P<0.01$.

$\S$ Statistically significant at $P<0.001$.

in their childhood. Of those who reported emotional abuse, 16.8\% (95\% CI 13.4\%-21.0\%) reported one incident, 24.8\% (95\% CI 20.7\%-29.5\%) reported few incidents and 58.3\% (95\% CI 53.2\%-63.2\%) reported many incidents. Girls in rural areas reported higher levels of emotional abuse compared to those in urban and peri-urban areas but this was not statistically significant.

\section{Emotionally abusive acts by family members compared to "others"}

The majority of emotionally abusive acts were carried out by extended family members. The most frequent perpetrators were female relatives $(27.8 \%, 95 \%$ CI $23.4 \%-32.6 \%)$, followed by male relatives (16.6\%, 95\% CI 13.0\%-20.8\%), biological mother (11.1\%, 95\% CI 8.45-14.5\%), biological father (9.8\%, 95\% CI $7.0 \%-13.4 \%)$, brother (4.7\%, 95\% CI 2.9\%-7.5\%) and sister (4.3\%, 95\% CI 2.5\%-7.4\%). Less frequent perpetrators were ex-partners (1.2\%, 95\% CI 0.4\%-3.5\%), step-mothers (6.5\%, 95\% CI 4.5\%$9.5 \%)$, teachers $(2.5 \%, 95 \%$ CI $1.4 \%-4.6 \%)$ and community leaders $(2.1 \%, 95 \%$ CI $1.2 \%-3.7 \%)$.

\section{Risk factors associated with emotional child abuse victimisation}

Using bivariate regressions, childhood emotional abuse was associated with physical and sexual childhood abuse, orphanhood, poverty, and frequent caregiver changes. Being close to one's mother was found to be protective against childhood emotional abuse as was being educated at tertiary level. Community trust, school trust, being close to one's father, relationship status, overcrowding and religious practice were not associated with emotional abuse (Table 2).

Using multivariate regressions controlling for age, location, faith, frequent caregiver changes (OR 1.42, 95\% CI 1.03-1.97), poverty (OR 1.51, 95\% CI 1.12-2.03), childhood physical abuse (OR 1.98, 95\% CI $1.45-2.71$ ) and sexual abuse (OR 2.22, 95\% CI 1.57-3.10) continued to be associated with an increased risk for childhood emotional abuse. Being close to one's mother (OR 0.88, 95\% CI 0.80-0.97) continued to be protective of emotional abuse. Orphanhood and tertiary-level education were no longer significant and therefore dropped from the model (Table 3, Model 3).

\section{Combinations of risk factors}

For female youth in Swaziland, the predicted probability of childhood emotional abuse victimisation was $13.0 \%$ (95\% CI 9.3\%-15.6\%) when none of the included risk factors of frequent caregiver changes, poverty, childhood physical and sexual abuse were present. One risk factor at a time was then included in a model, followed by a set of combinations of two, three and all four risk factors to establish which girls are at highest risk of emotional abuse.

Results for individual risk factors show the following predicted probabilities of emotional abuse expressed in percentages: $17.5 \%$ (95\% CI 11.6\%-23.3\%) for poverty; $18.3 \%$ (95\% CI 14.1\%-22.4\%) for frequent caregiver changes; $22.8 \%$ (95\% CI 15.6\%-30.0\%) for physical child abuse; and 24.9\% (95\% CI-19.4\%$30.0 \%)$ for sexual child abuse. When two risk factors were combined the predicted probabilities increased: 
$24.2 \%$ (95\% CI $17.3 \%-31.1 \%$ ) for frequent caregiver changes and poverty, 30.7\% (95\% CI 23.0\%$38.5 \%)$ for child physical abuse and hunger, $29.5 \%$ (95\% CI 20.2\%-39.0\%) for child physical abuse and frequent caregiver changes, 32\% (95\% CI 24.2\%-40.0\%) for child sexual abuse and frequent caregiver changes, $33.3 \%$ (95\% CI 27.1\%-39.5\%) for child sexual abuse and poverty and 39.6\% (95\% CI 31.1\%$48.1 \%$ ) for child sexual and physical abuse. The combination of three risk factors showed an increase of predicted probabilities as well: $38.7 \%$ (95\% CI 29.0\%-48.5\%) for physical abuse, frequent caregiver changes and poverty; $41.5 \%$ (95\% CI 33.0\%-50.0\%) for sexual abuse, frequent caregiver changes and poverty; $48.3 \%$ (95\% CI 38.8\%-57.7\%) for sexual abuse, physical abuse and frequent caregiver changes; and $49.7 \%$ (95\% CI 41.5\%-57.9\%) for sexual abuse, physical abuse and poverty. Finally, among girls who reported experiencing all four risk factors, predicted probability for childhood emotional abuse victimisation increased to $58.4 \%$ (95\% CI 49.8\%-67.1\%; Figure 1).

\section{Mental and sexual health outcomes associated with emotional abuse}

Using bivariate regressions, childhood emotional abuse was associated with the following health risks: suicide ideation, feeling depressed and having suffered from a sexually transmitted disease. Being HIV-positive, consuming alcohol and smoking were not associated with emotional abuse (Table 2).

Using multivariate regression analyses, suicidal ideation (OR 1.85, 95\% CI 1.30-2.63) and feeling depressed (OR 1.89, 95\% CI 1.31-2.71) were associated with emotional childhood abuse when controlling for location, age, faith, physical abuse and sexual abuse. Having a sexually transmitted disease was no longer significant and was therefore dropped from the model (Table 4, Model 2).

Table 4. Logistic regression analyses of health factors associated with emotional abuse among girls in Swaziland, $2007(n=1244)$

\begin{tabular}{lcccc} 
& \multicolumn{2}{c}{ MoDEL 1 } & \multicolumn{2}{c}{ ModEL 2 } \\
& Odds ratio & $\mathbf{9 5 \%}$ CI & Odds ratio & 95\% CI \\
Suicide ideation & $1.79^{*}$ & $1.25-2.56$ & $1.85^{*}$ & $1.30-2.63$ \\
\hline Feeling depressed & $1.87^{*}$ & $1.30-2.69$ & $1.89^{*}$ & $1.31-2.71$ \\
\hline Sexually transmitted disease & 1.78 & $0.90-3.55$ & & \\
\hline Physical abuse & $1.89^{*}$ & $1.38-2.58$ & $1.92^{*}$ & $1.40-2.62$ \\
\hline Sexual abuse & $2.04^{*}$ & $1.45-2.86$ & $2.08^{*}$ & $1.48-2.92$ \\
\hline Urban or peri-urban area & 0.78 & $0.53-1.16$ & & $0.84-94$ \\
\hline Age & $0.88^{*}$ & $0.84-.93$ & $0.89^{*}$ & \\
\hline Faith & 0.91 & $0.78-1.06$ & & \\
\hline
\end{tabular}

$\mathrm{CI}$ - confidence interval

* Statistically significant at $P<0.05$.

\section{DISCUSSION}

To the best of the authors' knowledge, this is the first and only nationally representative study of emotional child abuse victimisation in Swaziland. This study adds to the literature on the epidemiology of emotional child abuse victimisation in sub-Saharan Africa by investigating prevalence, risk factors and health outcomes associated with emotional child abuse. It finds high prevalence of emotional abuse and significant associations with hypothesized risk factors and indicators of poor health. In addition, a cumulative effect of risk factors for emotional abuse could be established.

Prevalence of emotional child abuse was high, with $28.5 \%$ of girls reporting at least one incident and $58.3 \%$ of these reporting many incidents. Results also show that physical and sexual child abuse are strongly associated with emotional child abuse, suggesting many instances of multiple abuse victimisation. This finding corresponds to reports from other cross-sectional studies in sub-Saharan Africa showing associations between emotional and physical and sexual child abuse [8]. Poly-victimisation affects large numbers of children across the world [30]. Children affected by one type of violence are often susceptible to other types of violence as these are mediated by common individual, family and social vulnerabilities [31]. In a recent study from South Africa, 35.5\% of children experienced more than five lifetime events of violence [32]. Factors associated with increased poly-victimisation in South Africa included parental substance use, parental absence due to illness, child substance use, child sexual risk behavior, single-parenting and living in urban areas [32]. 
Contrary to other research from the region [33], this study found female relatives to be the most common perpetrator of emotional abuse victimisation, followed by male relatives and biological parents. This may be due to family caregiving arrangements influenced by the high number of orphaned children in Swaziland, also found by this study. A large, national qualitative study on the drivers of violence affecting children in Swaziland, which included focus groups and interviews with 373 respondents, found that of all the interpersonal-level risk factors for violence against children suggested by respondents, family structure was the most cited. This is because "not living with biological parents" was perceived by many to almost guarantee negative differential treatment - which would be emotionally abusive at the least, but was also likely to result in a child being given a disproportionate number of household chores and harsher punishment [34]. While orphanhood was not associated with higher risk for emotional abuse in multivariate regressions, orphaned girls reported higher percentages of violence victimisation than non-orphans. This finding is consistent with a number of studies from sub-Saharan Africa [11,28,35,36]. However, these associations tend not to hold up in multivariate regressions controlling for other potential risk factors, which may drive risk for abuse more strongly than orphanhood alone. A recent systematic review examining risk for violence victimisation among orphaned and non-orphaned children found little or no difference in risk for abuse between the groups [37]. More research on the vulnerabilities of orphans is needed to better understand how orphanhood and violence interlink, particularly in countries with large numbers of orphans like Swaziland.

In line with high numbers of orphaned children, large numbers of girls reported frequent caregiver changes, and this type of social disadvantage is associated with emotional abuse. Conversely, being close to one's mother was a protective factor. The association between frequent caregiver changes and emotional abuse in Swaziland is particularly interesting considering that relatives in the extended family but not biological parents were the most commonly reported perpetrators of emotional abuse. This pattern contrasts with some findings in South Africa [33]. Future research should investigate whether these relatives are the primary caregivers of the child and, if so, how the child came to be in their care (ie, through orphanhood, abandonment, work or migration) as well as whether these abusive events occurred while the child was in the primary care of her biological parents or outside the household setting. Caregiving arrangements for girls should also be investigated to determine whether having kinship caregivers as opposed to non-kinship carers increases the odds of emotional abuse victimisation as has been found in qualitative research in Swaziland [34].

Overall, the findings correspond with research from South Africa where multiple victimisation, poverty and frequent caregiver changes were found to be associated with emotional abuse [11]. It is also likely that the specific context of Swaziland compounds these problems. Swaziland has a population of 1.3 million, $59.1 \%$ of whom live on less than US\$ 2 per day [38] and an estimated population of 120000 orphaned children [39]. The HIV prevalence in Swaziland is $27.4 \%$, which is the highest prevalence worldwide [40]. It is therefore likely that families experience multiple severe stressors such as extreme poverty, illness and death, resulting in insufficient care, disruption of social norms, and overburdened and underresourced systems for child protection [14,41-43]. Violence prevention interventions could thus be linked to HIV-prevention efforts through comprehensive social protection and social welfare efforts [44-46].

Contrary to other studies, overcrowding was not associated with emotional abuse in the multivariate analyses [8], which may be a result of the way in which this variable was measured. Establishing the highest number of residents in the household throughout one's lifetime may not be sensitive enough to establish whether the overcrowding was short-term or long-term.

Cumulative effects of risk factors on emotional abuse victimisation were found. Without any of the three significant risk factors, a girl's probability of experiencing childhood emotional abuse was 13\%, while girls who reported frequent moves, hunger, and physical and sexual childhood abuse had a probability of $58.4 \%$. The connections between adverse childhood experiences such as orphanhood, parental mental illness or childhood abuse, and putative outcomes have long been established in high income countries [47] with a growing evidence-base in low- and middle-income countries $[48,49]$. In particular, adults who experienced a combination of four or more adverse events in childhood are at risk for negative health outcomes.

Feelings of depression and suicidal ideation were also found to be associated with emotional abuse in this study. While more robust measures on mental health would need to be used in future studies to explore this relationship, this association has also been found in the evidence from the sub-Saharan African region [5] and across the globe [50]. Emotional childhood abuse may contribute to the salience of suicide as a leading cause of death for young people in southern Africa [51]. Sub-Saharan Africa experiences a high burden of child and adolescent mental health problems with a recent systematic review of commu- 
nity-based studies establishing a psychopathology prevalence rate of 14.3\% [52] but with little nationally representative data available from the region [53].

The results of this study suggest a need for comprehensive child abuse prevention and protection strategies for girls in Swaziland. Girls experiencing multiple adverse conditions are at high risk of abuse, and humiliating punishment of children is an accepted form of discipline in many Swazi households [17]. Holistic social support interventions that promote positive parenting behaviors of primary caregivers may be useful [54] and help to build stronger relationships between children and their caretakers, particularly mothers. A recent study from South Africa found adolescent health risks were linked to family disadvantage via abusive parenting and caregiver mental health problems, suggesting a need for combined parenting assistance, poverty alleviation and mental health support [10]. In particular, adolescent mothers are at high risk for harsh parenting [55], struggle with parenting stress [56], and experience high levels of poverty $[56,57]$ and low levels of education [58]. Considering the high risk for re-victimisation in victims of childhood violence $[50,59]$ and the possibility of inter-generational violence transmission to these girls' children [60], the high prevalence of abuse victimisation in this sample suggests that an entire society is persistently at risk for poor outcomes. Programmes are thus needed for both adult and adolescent mothers to reduce household stress and increase parenting capacity. Emerging evidence on parenting programmes with financial strengthening components for caregivers and teenagers shows clear reductions in physical and emotional abuse victimisation [61], also in the context of high levels of caregiver changes [62] in South Africa.

In light of the high levels of physical and sexual violence found in this study, a holistic approach to prevention is needed. As described in the INSPIRES framework, the seven strategies with the best available evidence for the reduction and prevention of violence against children across contexts are implementation of enforcement laws, changing of norms and values, safe environments, parent and caregiver support, income and economic strengthening, response and support services, and education and life skills, which should be implemented as part of a comprehensive and multi-sectoral plan [63]. However, each of these strategies need to be adapted and evaluated for the contexts in which there are to be used. Emerging research from other sub-Saharan countries suggests that prevention of violence against girls should incorporate asset-based approaches. Protective assets can be income generating activity, friendship networks, specific knowledge of one's community, services and rights, enabling girls to make safety plans, and creating safe spaces [64]. In Swaziland specifically, a school-based intervention of "Safer Spaces" showed stark increases in girls' protective assets and in knowledge about gender-based violence. Furthermore, changes in gendered attitudes were observed, which is often the first stage in normative transformations around violence. However, reporting of violence increased and no reductions in victimisation were shown [65]. Early results from other countries in sub-Saharan Africa show a potential for using protective assets to prevent gender-based violence [64], early child marriage [66] and HIV-risk [67]. However, further research and large-scale intervention evaluation are needed in order to verify the impact of parenting interventions and protective assets on child abuse prevention.

Research in sub-Saharan Africa has consistently shown the impact of violence on educational attainment $[68,69]$ as well as the protective effect of secondary education on harsh parenting in adulthood [70] and exposure to intimate partner violence [71]. A case could thus be made that secondary schooling - provided the school setting is safe and protective as indicated in the Safe Spaces Intervention - is another important child abuse prevention intervention.

In order to address the multiple needs of young women and children in Swaziland, an integrated, early intervention approach may be effective. This holistic approach could give ample opportunity for different services providers to collaborate and address multiple forms of violence using gender-sensitive approaches. Where strong links are built between services for women and children as well as between school-based and parenting programmes, complex family dynamics may be addressed, and continued programming for adolescent health and development with gender-sensitive content could be facilitated.

\section{Limitations and future research}

This study had a number of limitations. First, an all-female sample was recruited so no assumptions regarding the victimisation of boys can be made. Second, data were cross-sectional and therefore did not allow for causal inferences. Further, it is impossible to say in what temporal order risk factors and putative health outcomes occurred. In other words, we cannot know if children experience suicidal ideation because they were victims of violence or if they are more vulnerable to experience violence. Third, the study used retrospective self-report which may be subject to recall bias due to under-reporting of abusive events [72]. Furthermore, the study used interviewer-guided questionnaires, which may have resulted in some under-reporting due to social desirability bias in particular with regards to sensitive ques- 
tions such as parental aggression and sexual violence. However, official records are not kept reliably in Swaziland, and few child abuse victims access services [73], thus making self-report a more reliable source of information. Further, the study did not use internationally validated measures of child abuse victimisation and mental health. For example, emotional abuse was measured using one item that grouped many emotionally abusive acts in one question. While different abuse measures use differing definitions of emotional abuse, there is large overlap between the abusive incidents queried in the single-item question and the most common child abuse measures. However, including four types of abusive behavior in a single question might have made this question too complex and thus led to over- or under-reporting of abusive events. Depression was measured with only one question about whether the participant had felt depressed. Validity of these single items as indicators of complex constructs is not established. Although these single-item measures have been used in multiple VAC studies in sub-Saharan Africa and elsewhere [27] since the completion of this study and the basic trends in prevalence may be similar to regional surveys that used more comprehensive measures, ie, Optimus Study in South Africa [74], future research should develop and utilize validated and standardised measures. Finally, there is a strong likelihood for unmeasured confounding in this study. Even though models adjusted for potential confounding, no such adjustment was possible for caregiver-related variables commonly associated with emotional abuse victimisation (ie, mental health problems, drug abuse) or community factors (ie, social norms, service availability, girls' knowledge of services).

\section{CONCLUSIONS}

Overall, the findings of this study demonstrate the magnitude of girls' exposure to emotional abuse in Swaziland. It highlights particularly vulnerable groups such as victims of multiple types of abuse, those who experienced frequent caregiver changes and those most affected by poverty. The findings are relevant to social policy and intervention programmes. Holistic child abuse prevention programmes targeting poverty, unstable family environments and parenting — such as cash transfers and programmes focused on keeping girls in education, teaching parenting skills and delaying marriage-are needed to reduce the burden of emotional abuse and associated adverse mental health outcomes.

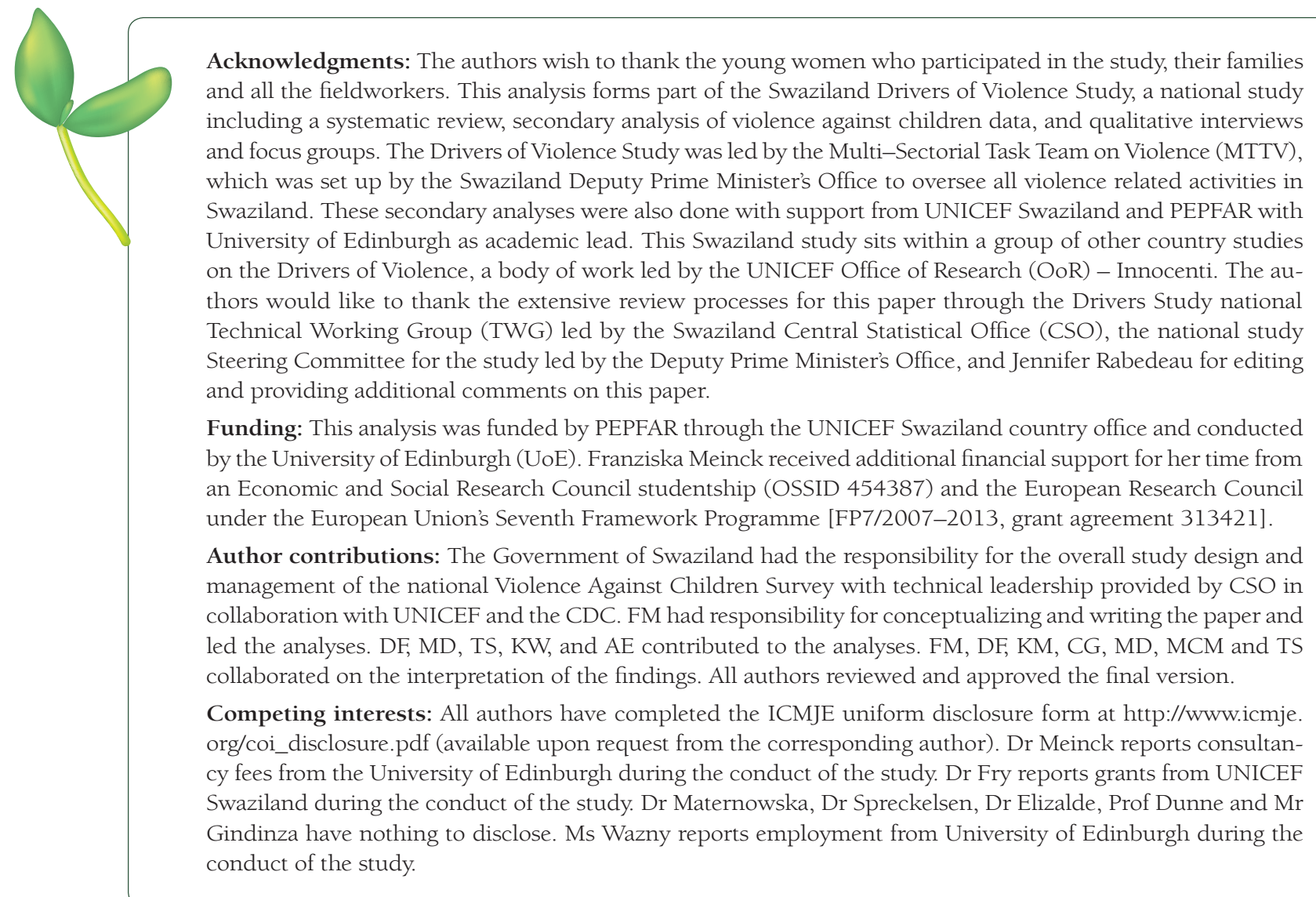


1 UNICEF. Hidden in Plain Sight: A statistical analysis of violence against children. 2014. Available: https://www.unicef. org/publications/index_74865.html. Accessed: 1 October 2014.

2 Stoltenborgh M, van IJzendoorn MH, Euser EM, Bakermans-Kranenburg MJ. A global perspective on child sexual abuse: Meta-analysis of prevalence around the world. Child Maltreat. 2011;16:79-101. Medline:21511741 doi:10.1177/1077559511403920

3 Akmatov MK. Child abuse in 28 developing and transitional countries—results from the Multiple Indicator Cluster Surveys. Int J Epidemiol. 2011;40:219-27. Medline:20943933 doi:10.1093/ije/dyq168

4 Morojele NK, Brook JS. Substance use and multiple victimisation among adolescents in South Africa. Addict Behav. 2006;31:1163-76. Medline:16253426 doi:10.1016/j.addbeh.2005.09.009

5 Cluver LD, Orkin F, Boyes M, Sherr L. Child and adolescent suicide attempts, suicidal behavior, and adverse childhood experiences in South Africa: a prospective study. J Adolesc Health. 2015;57:52-9. Medline:25936843 doi:10.1016/j. jadohealth.2015.03.001

6 Jewkes R, Levin J, Mbananga N, Bradshaw D. Rape of girls in South Africa. Lancet. 2002;359:319-20. Medline:11830201 doi:10.1016/S0140-6736(02)07530-X

7 Cluver L, Orkin M, Boyes M, Gardner F, Meinck F. Transactional sex amongst AIDS-orphaned and AIDS-affected adolescents predicted by abuse and extreme poverty. J Acquir Immune Defic Syndr. 2011;58:336-43. Medline:21857361 doi:10.1097/QAI.0b013e31822f0d82

8 Meinck F, Cluver L, Boyes M, Mhlongo E. Risk and protective factors for physical and sexual abuse of children and adolescents in Africa: a review and implications for practice. Trauma Violence Abuse. 2015;16:81-107. Medline:24648489 doi:10.1177/1524838014523336

9 Oladeji BD, Mkanjoula V, Gureje O. Family-related adverse childhood experiences as risk factors for psychiatric disorders in Nigeria. Br J Psychiatry. 2010;196:186-91. Medline:20194539 doi:10.1192/bjp.bp.109.063677

10 Meinck F, Cluver L, Orkin M, Kuo C, Dhar Sharma A, Hensels I, et al. Pathways from family disadvantage via harsh parenting and caregiver mental health distress to adolescent health risks in South Africa. J Adolesc Health. 2017;60:57-64. Medline:27793729 doi:10.1016/j.jadohealth.2016.08.016

11 Meinck F, Cluver LD, Boyes M, Ndhlovu L. Risk and protective factors for physical and emotional abuse victimisation amongst vulnerable children in South Africa. Child Abuse Rev. 2015;24:182-97. doi:10.1002/car.2283

12 Madu SN. The relationship between parental physical availability and child sexual, physical and emotional abuse: A study among a sample of university students in South Africa. Scand J Psychol. 2003;44:311-8. Medline:12887552 doi:10.1111/1467-9450.00350

13 Madu S, Idemudia S, Jegede A. Perceived parental disorders as risk factors for child sexual, physical and emotional abuse among high school students in the Mpumalanga Province, South Africa. J Soc Sci. 2002;6:103-12.

14 Meinck F, Cluver L, Boyes M. Household illness, poverty and physical and emotional child abuse victimisation: findings from South Africa's first prospective cohort study. BMC Public Health. 2015;15:444. Medline:25924818 doi:10.1186/ s12889-015-1792-4

15 Thurman T, Kidman R. Child maltreatment at home: Prevalence among orphans and vulnerable children in KwaZuluNatal, South Africa. Tulane University. 2011. Available: http://www2.tulane.edu/publichealth/ghsd/upload/Child-maltreatment-at-home_2011.pdf. Accessed: 1 November 2011.

16 Dlamini Q. Students abuse by teachers in the Shiselweni Region High Schools. University of Swaziland; 2010.

17 Clacherty G, Donal D, Clacherty A. Children's experiences of corporal punishment in Swaziland. Mbabane: Save the Children; 2005.

18 Kanduza A, Mamba T, Ndlangamandla S, Vilakazi L, Zungo H. The scourge of abuse amongst school going children in Swaziland. 2003. Available: http://www.infocenter.nercha.org.sz/node/334. Accessed: 1 June 2015.

19 Reza A, Breiding M, Blanton C, Mercy J, Dahlberg L, Anderson M, et al. A national study on violence against children and young women in Swaziland. UNICEF. 2007. Available: https://www.unicef.org/swaziland/Violence_study_report. pdf. Accessed: 2 June 2016.

20 Kish L. A procedure for objective respondent selection within the household. J Am Stat Assoc. 1949;44:380-7. doi:10. 1080/01621459.1949.10483314

21 Reza A, Breiding M, Gulaid J, Mercy J, Blanton C, Mthethwa Z, et al. Sexual violence and its health consequences for female children in Swaziland: a cluster survey study. Lancet. 2009;373:1966-72. Medline:19428100 doi:10.1016/S01406736(09)60247-6

22 Breiding MJ, Reza A, Gulaid J, Blanton C, Mercy J, Dahlberg L, et al. Risk factors associated with sexual violence towards girls in Swaziland. Bull World Health Organ. 2011;89:203-10. Medline:21379416 doi:10.2471/BLT.10.079608

23 Breiding MJ, Mercy J, Gulaid J, Reza A, Hleta-Nkambule N. A national survey of childhood physical abuse among females in Swaziland. J Epidemiol Glob Health. 2013;3:73-81. Medline:23856568 doi:10.1016/j.jegh.2013.02.006

24 World Health Organization. Putting women first: ethical and safety recommend for research on domestic violence against women. 2001. Available: http://www.who.int/gender/violence/womenfirtseng.pdf. Accessed: 2 June 2016.

25 Jansen HAFM; World Health Organization. "Putting women first" ethical and safety recommendations for research on domestic violence against women. 2006. Available: http://www.who.int/reproductivehealth/publications/violence/intervention-research-vaw/en/. Accessed: 2 June 2015.

26 UNAIDS. Children on the Brink 2004: A joint report of new orphan estimates and a framework for action. 2004. Available: https://www.unicef.org/publications/index_22212.html. Accessed: 6 June 2015. 
27 UNICEF. CDC. Violence against children and young women in Malawi: Findings from a national survey. 2013. Available: https://www.unicef.org/malawi/MLW_resources_violencereport.pdf/. Accessed: 2 June 2015.

28 UNICEF. Violence against children in Tanzania: Findings from a national survey, 2009. 2011. Available: https://www. unicef.org/media/files/VIOLENCE_AGAINST_CHILDREN_IN_TANZANIA_REPORT.pdf. Accessed: 2 June 2016.

29 Hosmer D, Lemeshow S. Applied logistic regression. New York: John Wiley \& Sons; 1989.

30 Finkelhor D, Ormrod R, Turner H. Poly-victimization: a neglected component in child victimization. Child Abuse Negl. 2007;31:7-26. Medline:17224181 doi:10.1016/j.chiabu.2006.06.008

31 Finkelhor D, Ormrod R, Turner H, Holt M. Pathways to poly-victimization. Child Maltreat. 2009;14:316-29. Medline:19837972 doi:10.1177/1077559509347012

32 Leoschut L, Kafaar Z. The frequency and predictors of poly-victimisation of South African children and the role of schools in its prevention. Psychol Health Med. 2017;22(sup1):81-93.

33 Meinck F, Cluver L, Boyes M, Loening-Voysey H. Physical, emotional and sexual adolescent abuse victimisation in South Africa: prevalence, incidence, perpetrators and locations. J Epidemiol Community Health. 2016;70:910-6. Medline:26962202 doi:10.1136/jech-2015-205860

34 The Swaziland Deputy Prime Minister's Office, University of Edinburgh, University of Swaziland, UNICEF. A National Study on the Drivers of Violence Affecting Children in Swaziland. Mbabane: UNICEF Swaziland; 2017.

35 UNICEF. Violence against children in Kenya: Findings from a 2010 National Survey. 2012. Available: https://www.unicef.org/esaro/VAC_in_Kenya.pdf. Accessed: 6 June 2015.

36 Birdthistle IJ, Floyd S, Mwanasa S, Nyagadza A, Gwiza E, Glynn J. Child sexual abuse and links to HIV and orphanhood in urban Zimbabwe. J Epidemiol Community Health. 2011;65:1075-82. Medline:20628080 doi:10.1136/ jech.2009.094359

37 Nichols J, Embleton L, Mwangi A, Morantz G, Vreeman R, Ayaya S, et al. Physical and sexual abuse in orphaned compared to non-orphaned children in sub-Saharan Africa: a systematic review and meta-analysis. Child Abuse Negl. 2014:38:304-16. Medline:24210283 doi:10.1016/j.chiabu.2013.09.012

38 World Bank. World Bank development indicators. 2015. Available from: http://data.worldbank.org/indicator/SI.POV.2DAY/ countries. Accessed: 13 July 2015.

39 UNICEF. Country statistics. 2013. Available: https://www.unicef.org/statistics/index_countrystats.html. Accessed: 13 July 2015.

40 UNAIDS. HIV and AIDS estimates. 2015. Available: http://www.unaids.org/en/regionscountries/countries/. Accessed: 13 July 2015.

41 Lachman JM, Cluver L, Boyes M, Kuo C, Casale M. Positive parenting for positive parents: HIV/AIDS, poverty, caregiver depression, child behavior, and parenting in South Africa. AIDS Care. 2014;26:304-13. Medline:23930647 doi:10.108 0/09540121.2013.825368

42 Ward C, Mikton C, Cluver L, Cooper P, Gardner F, Hutchings J, et al. Parenting for lifelong health: from South Africa to other low- and middle-income countries. Early Child Matters. 2014;122:49-53.

43 Kuo C, Operario D. Health of adults caring for orphaned children in an HIV-endemic community in South Africa. AIDS Care. 2011;23:1128-35. Medline:21480009 doi:10.1080/09540121.2011.554527

44 Cluver LD, Orkin FM, Meinck F, Boyes ME, Yakubovich AR, Sherr L, et al. Can social protection improve Sustainable Development Goals for adolescent health? PLoS One. 2016;11:e0164808. Medline:27749932 doi:10.1371/journal. pone.0164808

45 Cluver LD, Orkin F, Meinck F, Boyes M, Sherr L. Structural drivers and social protection: mechanisms of HIV risk and HIV prevention for South African adolescents. J Int AIDS Soc. 2016;19:20646. Medline:27086838 doi:10.7448/ IAS.19.1.20646

46 Long S, Bunkers K. Building Protection and Resilience: Synergies for Child Protection Systems and Children Affected by HIV and AIDS. AIDS I-ATT (IATT) on C and HIV and, editor. New York: UNICEF; 2013.

47 Anda RF, Felitti V, Bremner J, Walker J, Whitfield C, Perry B, et al. The enduring effects of abuse and related adverse experiences in childhood. Eur Arch Psychiatry Clin Neurosci. 2006;256:174-86. Medline:16311898 doi:10.1007/s00406005-0624-4

48 Bruwer B, Govender R, Bishop M, Williams DR, Stein DJ, Seedat S. Association between childhood adversities and longterm suicidality among South Africans from the results of the South African Stress and Health study: a cross-sectional study. BMJ Open. 2014;4:e004644. Medline:24919638 doi:10.1136/bmjopen-2013-004644

49 Tran QA, Dunne M, Luu N. Adverse childhood experiences and the health of university students in eight provinces of Vietnam. Asia Pac J Public Health. 2015;27(8_suppl):26S-32S. Medline:26047629 doi:10.1177/1010539515589812

50 Norman RE, Byambaa M, De R, Butchart A, Scott J, Vos T. The long-term health consequences of child physical abuse, emotional abuse, and neglect: a systematic review and meta-analysis. PLoS Med. 2012;9:e1001349. Medline:23209385 doi:10.1371/journal.pmed.1001349

51 Mathews S, Martin L, Scott C, Coetzee D, Lake L. Every child counts: Lessons learned from the South African Child Death Review pilot. Cape Town: University of Cape Town; 2015.

52 Cortina MA, Sodha A, Fazel M, Ramchandani PG. Prevalence of child mental health problems in sub-Saharan Africa. Arch Pediatr Adolesc Med. 2012;166:276-81. Medline:22393184 doi:10.1001/archpediatrics.2011.592

53 Erskine HE, Baxter AJ, Patton G, Moffitt TE, Patel V, Whiteford HA, et al. The global coverage of prevalence data for mental disorders in children and adolescents. Epidemiol Psychiatr Sci. 2016;20:1-8. Medline:26786507 doi:10.1017/ S2045796015001158 
54 Mikton C, Butchart A. Child maltreatment prevention: a systematic review of reviews. Bull World Health Organ. 2009;87:353-61. Medline:19551253 doi:10.2471/BLT.08.057075

55 Lee Y. Early motherhood and harsh parenting: the role of human, social, and cultural capital. Child Abuse Negl. 2009;33:625-37. Medline:19818500 doi:10.1016/j.chiabu.2009.02.007

56 Kaye DK. Negotiating the transition from adolescence to motherhood: coping with prenatal and parenting stress in teenage mothers in Mulago hospital, Uganda. BMC Public Health. 2008;8:83. Medline:18318894 doi:10.1186/1471-24588-83

57 Mchunu G, Peltzer K, Tutshana B, Seutlwadi L. Adolescent pregnancy and associated factors in South African youth. Afr Health Sci. 2012;12:426-34. Medline:23515418

58 Panday S, Makiwane M, Ranchod C, Letsoalo T. Teenage pregnancy in South Africa - with a specific focus on schoolgoing learners. Pretoria: Human Sciences Research Council \& Department of Basic Education; 2009.

59 Gilbert R, Widom CS, Browne K, Fergusson D, Webb E, Janson S. Burden and consequences of child maltreatment in high-income countries. Lancet. 2009;373:68-81. Medline:19056114 doi:10.1016/S0140-6736(08)61706-7

60 McCloskey L, Bailey J. The intergenerational transmission of risk for child sexual abuse. J Interpers Violence. 2000;15:101935. doi:10.1177/088626000015010001

61 Cluver L, Lachman J, Ward C, Gardner F, Peterson T, Hutchings JM, et al. Development of a parenting support program to prevent abuse of adolescents in South Africa: findings from a pilot pre-post study. Res Soc Work Pract. 2016;26:1049731516628647

62 Cluver L, Meinck F, Shenderovich Y, Ward CL, Romero RH, Redfern A, et al. A parenting programme to prevent abuse of adolescents in South Africa: study protocol for a randomised controlled trial. Trials. 2016;17:328. Medline:27435171 doi:10.1186/s13063-016-1452-8

63 World Health Organziation. INSPIRE: seven strategies for ending violence against children. Geneva: WHO; 2016.

64 Bruce J. Violence against adolescent girls: a fundamental challenge to meaningful equality. Population Council. 2012. Available: http://www.ungei.org/index_5771.html. Accessed: 6 June 2015.

65 Swaziland Action Group Against Abuse (SWAGAA). Effectiveness of a comprehensive sexual and gender-based violence prevention project for in-school girls in Swaziland. Manzini: SWAGGA; 2013.

66 Erulkar AS, Muthengi E. Evaluation of Berhane Hewan: a program to delay child marriage in rural Ethiopia. Int Perspect Sex Reprod Health. 2009;35:6-14. Medline:19465343 doi:10.1363/3500609

67 Dupas P. Do teenagers respond to HIV risk information? Evidence from a field Experiment in Kenya. Am Econ J Appl Econ. 2011;3:1-34. Medline:22199993 doi:10.1257/app.3.1.1

68 Sherr L, Hensels I, Skeen S, Tomlinson M, Roberts K, Macedo A. Exposure to violence predicts poor educational outcomes in young children in South Africa and Malawi. Int Health. 2016;8:36-43. Medline:26678567

69 Pieterse D. Childhood maltreatment and educational outcomes: evidence from South Africa. Health Econ. 2015;24:87694. Medline:24890398 doi:10.1002/hec.3065

70 World Health Organization. World Report on Violence and Health: Chapter 3 Child abuse and neglect by parents and other caregivers. Geneva: WHO; 2002.

71 Abramsky T, Watts CH, Garcia-Moreno C, Devries K, Kiss L, Ellsberg M, et al. What factors are associated with recent intimate partner violence? Findings from the WHO multi-country study on women's health and domestic violence. BMC Public Health. 2011;11:109.

72 Hardt J, Rutter M. Validity of adult retrospective reports of adverse childhood experiences: review of the evidence. J Child Psychol Psychiatry. 2004:45:260-73. Medline:14982240 doi:10.1111/j.1469-7610.2004.00218.x

73 Sumner SA, Mercy J, Saul J, Motsa-Nzuza N, Kwesigabo G, Buluma M, et al. Prevalence of sexual violence against children and use of social services — seven countries, 2007-2013. MMWR Morb Mortal Wkly Rep. 2015;64:565-9. Medline:26042646

74 Artz L, Burton P, Ward CL, Leoschut L, Phyfer J, Loyd S, et al. Optimus Study South Africa: Technical Report Sexual victimisation of children in South Africa. Zurich: UBS Optimus Foundation; 2016. 